\title{
Análise do repertório de habilidades sociais de pessoas com síndrome de Down
}

\author{
Analysis of the repertoire of social skills of people with Down syndrome
}

Análisis de la repertorio de las habilidades sociales de las personas con el síndrome de Down

* Viviane Rodrigues

Professora doutora na Faculdades Integradas de Jaú, Jaú, São Paulo, Brasil.

viviane_reb@hotmail.com

** Bruna Bianchi

Graduanda na Universidade Federal de São Carlos (UFSCar), São Carlos, São Paulo, Brasil. bruna_1996.b@hotmail.com

\section{*** Gabriela Cometa Aissa}

Graduanda na Universidade Federal de São Carlos (UFSCar), São Carlos, São Paulo, Brasil. gabicometa@gmail.com

\section{**** Stefany Gabrielly Pereira de Souza}

Graduandana Universidade Federal de São Carlos (UFSCar), São Carlos, São Paulo, Brasil.

stefany_gsouza@hotmail.com

\section{***** Márcia Duarte Galvani}

Professora doutorana Universidade Federal de São Carlos (UFSCar), São Carlos, São Paulo, Brasil. marciaduar@yahoo.com.br

Recebido: 8 de maio de 2018

Aprovado: 15 de outubro de 2018

\section{RESUMO}

Pessoas com síndrome de Down (SD) apresentam déficits nas habilidades sociais envolvendo relações de amizade, vida acadêmica, namoro, dentre outras. No entanto, há uma escassez de estudos que envolvem a percepção da pessoa com SD em relação às suas habilidades sociais. Neste sentido, o objetivo desse trabalho foi desenvolver um instrumento de avaliação das habilidades sociais capaz de avaliar a percepção da própria pessoa com SD, além de verificar o repertório de habilidades sociais das pessoas com SD a partir da percepção de seus pais e pessoas próximas. Participaram da pesquisa 15 pessoas, sendo cinco com síndrome de Down, com idades entre 15 e 35 anos, cinco pessoas próximas (uma para cada participante com SD), e os pais ou responsáveis das pessoas com síndrome de Down (somente um de cada pessoa com SD). Foram utilizados os seguintes instrumentos: Planilha de seleção de pessoas mais próximas; Questionário de Habilidades Sociais; Avaliação de Habilidades Sociais por meio de vídeos modelos; Roteiro de observação. Para 
DOI: $10.5902 / 1984686 \times 27836$

tanto, foi empregada a pesquisa descritiva e como procedimentos de análise dos dados, utilizou-se a análise de conteúdo. Os resultados apontaram que o vídeo em formato visual e dinâmico favoreceu a compreensão e a atenção dos participantes, possibilitando condições de responderem com mais fidedignidade às questões da avaliação. Concluiu-se que este estudo pode contribuir para o levantamento das habilidades sociais que necessitam de intervenção, a partir das respostas fornecidas pelas pessoas com SD, seus responsáveis e pessoas próximas a eles e que cada pessoa com SD tem suas particularidades.

Palavras-chave: Educação especial; Síndrome de Down; Habilidades sociais.

\section{ABSTRACT}

People with Down syndrome (DS) have deficits in social skills involving friendship relations, academic life, dating, among others. However, there is a shortage of studies that involve the perception of the person with DS in relation to their social skills. In this sense, the objective of this research was to develop an instrument of social skills evaluation capable of assessing the perception of the person with DS, as well as to verify the repertoire of social skills of people with DS from the perception of their parents and close people. Fifteen people participated in the research, of these, five with Down syndrome, aged 15-35 years, five close people (one for each participant with DS) and the parents or responsible of people with DS (only one of each person with DS). The following instruments were used: Nearest people selection worksheet; Social Competence Questionnaire; Evaluation of Social Competences through model videos; Observation Roadmap. Therefore, descriptive research was employed and as data analysis procedures, content analysis was used. The results pointed that the video in visual and dynamic format favored the participants' understanding and attention, enabling them to respond more reliably to the evaluation questions. As a conclusion, this study may contribute to the survey of social skills that need intervention, based on the answers provided by people with DS, their responsible and close people to them and each person with DS has your peculiarities.

Keywords: Special education; Down syndrome; Skills social.

\section{RESUMEN}

Las personas con síndrome de Down (SD) tienen deficiencias en las habilidades sociales que involucran relaciones de amistad, vida académica, citas, entre otros. Sin embargo, hay una escasez de estudios que involucren la percepción de la persona con SD en relación con sus habilidades sociales. En este sentido, el objetivo de esta investigación fue desarrollar un instrumento de evaluación de habilidades sociales capaz de evaluar la percepción de la persona con SD, así como verificar el repertorio de habilidades sociales de las personas con SD desde la percepción de sus padres y gente cercana. Quince personas participaron en la investigación, de ellas, cinco con síndrome de Down, de 15 a 35 años, cinco personas cercanas (una para cada participante con SD) y los padres o responsables de personas con SD (solo una de cada persona con SD). Se utilizaron los siguientes instrumentos: Hoja de trabajo de selección de personas más cercanas; Cuestionario de Competencia Social; 
DOI: $10.5902 / 1984686 \times 27836$

Evaluación de Competencias Sociales a través de videos modelo; Hoja de ruta de la observación. Por lo tanto, se empleó la investigación descriptiva y, como procedimientos de análisis de datos, se utilizó el análisis de contenido. Los resultados señalaron que el video en formato visual y dinámico favoreció la comprensión y atención de los participantes, permitiéndoles responder de manera más confiable a las preguntas de la evaluación. Como conclusión, este estudio puede contribuir a la encuesta de habilidades sociales que necesitan intervención, en función de las respuestas proporcionadas por las personas con SD, sus responsables y personas cercanas a ellas y cada persona con DS tiene sus particularidades. Palabras clave: Educación especial; Síndrome de Down; Habilidades sociales.

\section{Introdução}

O desenvolvimento social de um indivíduo começa a partir do nascimento e com o passar do tempo, as habilidades sociais se tornam mais elaboradas, sendo a infância um período crítico com relação à aprendizagem das habilidades sociais. Considera-se que grande parte da aprendizagem das crianças está relacionada à sua observação com relação ao comportamento de seus pais, imitando-os. Os pais modelam o comportamento de seus filhos reagindo de maneiras específicas às manifestações das habilidades deles, começam então a dar instruções (estímulos) para que tais comportamentos ocorram (DEL PRETTE; DEL PRETTE, 1999). Além dos pais, os pares têm um significado enorme no desenvolvimento das habilidades sociais. As interações com extrafamiliares sempre impõe novos desafios interpessoais (DEL PRETTE; DEL PRETTE, 1999).

Algumas falhas na aprendizagem do comportamento social podem ocorrer devido a diferentes fatores, como restrições de oportunidades de experiências devido à pobreza, ou também por normas e valores culturais, podem ocorrer por relações familiares enfraquecidas, como por exemplo, um pai agressivo que tem um comportamento inapropriado de interação, ou por práticas familiares que premiam as crianças que são dependentes e obedientes e reprimem aquelas que têm um comportamento de iniciar o contato social, ou por ter dificuldades na aprendizagem, como ter deficiência intelectual e dificuldades para resolver problemas como, por exemplo, as pessoas com síndrome de Down (SD) (DEL PRETTE; DEL PRETTE, 1999).

As limitações nas habilidades de linguagem presentes nas pessoas com SD podem comprometer a aquisição de sistemas simbólicos e consequentemente o desenvolvimento das habilidades sociais (QUITÉRIO, 2010). Segundo Greenspan e Granfield (1992), ao retomar a definição de deficiência intelectual é possível observar que as pessoas com 
DOI: $10.5902 / 1984686 \times 27836$

deficiência intelectual apresentam limitações nas habilidades adaptativas que envolvem as áreas conceituais, sociais e práticas. Em consonância, Soresi e Nota (2000), afirmam, por meio da literatura, que na infância e na vida adulta, as pessoas com deficiência intelectual apresentam interações sociais pobres e inadequadas ao serem comparadas com crianças com desenvolvimento típico, além de que durante a infância revelam poucos contatos sociais, brincadeiras em grupo e poucas respostas positivas quando são convidados por outros. As autoras mostraram que as pessoas com SD apresentam dificuldades em duas áreas do comportamento que são cruciais para a adaptação social: relacionamento com pares e relacionamento com professores, essas dificuldades diminuem a qualidade das experiências sociais, resultando em efeitos negativos para adaptação e interação social em sua vida adulta.

Pereira- Silva e Dessen (2003), Soresi e Nota (2000) afirmaram que a concepção de que as pessoas com SD são dóceis, carinhosas e cooperativas não é um consenso, pois um comportamento não é determinado somente por uma alteração genética, ou seja, ao se dizer que as pessoas com SD são dóceis, carinhosas e cooperativas, desconsidera-se as influências do ambiente social em relação a seu comportamento. Os estímulos que a pessoa recebe ao longo da vida terão grande influência sobre seu comportamento. Contudo, somente é possível ter uma visão mais global da concepção da pessoa com SD a partir da interpretação das consequências advindas tanto da alteração genética quanto das influências do ambiente social.

A aprendizagem das habilidades sociais geralmente é estimulada em crianças com síndrome de Down por meio de programas de intervenção precoce, treinamento de habilidades sociais e habilidades acadêmicas na idade escolar. Contudo, não há evidências de que os adolescentes e adultos com SD realmente desenvolvem as habilidades necessárias para uma vida independente quando adultos. Em se tratando da infância, há um consenso de que as crianças com SD apresentam limitações significativas nas habilidades sociais. Entretanto, evidências sobre o desenvolvimento geral e funcionamento social na adolescência e idade adulta são limitadas (VAN GAMEREN-OOSTEROM et al., 2013).

Estudos acerca das habilidades sociais de adolescente e adultos com síndrome de Down são escassos tanto na literatura nacional como na literatura internacional. Van Gameren-Oosterom et al. (2013), realizaram um estudo com 322 adolescentes com idades entre 16 e 19 anos e puderam demonstrar a grande necessidade do desenvolvimento de 
DOI: $10.5902 / 1984686 \times 27836$

habilidades funcionais, incluindo as habilidades sociais, para que estes pudessem ter uma vida mais independente.

Os relacionamentos interpessoais de adolescentes com SD, foi objeto de estudo de Bonomo, Garcia e Rosseti (2009). Estes autores realizaram entrevistas semiestruturadas com 10 adolescentes de 13 a 19 anos e com suas respectivas mães. As entrevistas enfatizaram questões de amizade. Como resultados, relataram que os adolescentes possuem amigos, entretanto, esta amizade se caracteriza por atitudes de ajuda e companheirismo. Foram relatadas poucas atividades em contextos outros que não a escola, apontando exclusão destes adolescentes com SD por seus pares.

Angélico e Del Prette (2011), ao avaliarem o repertório de habilidades sociais em dez adolescentes com SD e considerarem as proposições da literatura, demonstraram, após observações de filmagens, o desempenho dos participantes com relação às habilidades sociais (comunicativas, de civilidade, assertivas de enfrentamento, empáticas, de expressão de sentimento positivo). Contudo, como resultados descreveram que a maioria apresentou déficits nas respostas que envolviam as habilidades de enfrentamento, considerando que é uma habilidade que indica a necessidade de intervenções preventivas e educacionais.

As dificuldades encontradas pelos indivíduos com relação às habilidades sociais não são distúrbios ou patologia, no entanto elas minimizam a qualidade de vida das pessoas, fazendo com que precisem de intervenções preventivas e educacionais. Porém, quando essas dificuldades progridem, tanto na duração quanto na frequência de episódios, é hora de requerer uma intervenção terapêutica imediatamente. A evidência atual sobre 0 funcionamento prático e social da pessoa com SD, concentra-se nas competências durante a infância, mostrando um atraso em todas as crianças, mas com uma variabilidade considerável (VAN GAMEREN-OOSTEROM et al., 2013). Já as evidências na adolescência e vida adulta referente às habilidades sociais é bastante limitada.

Anteriormente a qualquer intervenção com relação às habilidades sociais voltadas às pessoas com SD, a observação sistemática é a primeira que possibilitará o acesso às habilidades sociais (GRESHAM, 2000). Entretanto, faz-se necessária uma avaliação que contemple também a opinião/concepção da própria pessoa com SD e seja um complemento da observação sistemática.

As crianças com síndrome de Down apresentam deficiência intelectual, aprendem em um ritmo próprio e apresentam dificuldades em raciocínios complexos e juízo crítico (KOZMA, 2007). Neste sentido, as autoavaliações a serem realizadas com este público 
DOI: $10.5902 / 1984686 \times 27836$

devem considerar as suas dificuldades de aprendizagem, prezando por uma linguagem de fácil compreensão. Uma avaliação que seja capaz de acessar a concepção da própria pessoa com SD poderá contribuir para futuros programas de intervenção que sejam mais adequados às necessidades desse público. Segundo Bonomo, Garcia e Rossetti (2009), os adolescentes com SD que participaram de seus estudos tiveram dificuldade na compreensão de algumas perguntas da entrevista utilizada.

Del Prette e Del Prette (2006) afirmam que ao se estudar a habilidade social é imprescindível a utilização de diferentes instrumentos (avaliação multimodal), devido à multidimensionalidade das habilidades sociais. A avaliação multimodal envolve o uso de diferentes instrumentos, em diferentes ambientes e com diferentes parceiros como: os pais, professores e colegas, além da própria pessoa, para que futuramente, tenha-se uma intervenção mais eficaz.

A partir da escassez de estudos que envolvam a concepção da própria pessoa com SD a respeito de suas habilidades sociais, além de poucos estudos que envolvam adolescentes e adultos com SD, este estudo poderá possibilitar uma estratégia de avaliação que proporcione uma melhor compreensão da pessoa com SD com relação às questões, além de buscar compreender como elas se relacionam no meio em que vivem, com as pessoas que as rodeiam.

\section{Objetivo}

Neste sentido, o objetivo desse trabalho foi desenvolver um instrumento de avaliação das habilidades sociais capaz de avaliar a percepção da própria pessoa com SD, além de verificar o repertório de habilidades sociais das pessoas com SD a partir da percepção de seus pais e pessoas próximas.

\section{Método}

\section{Caracterização da Pesquisa}

Este estudo é caracterizado como uma pesquisa descritiva em que se observa os fatos, registra-os, analisa e os correlacionam. Assim, busca-se conhecer as diversas situações e "demais aspectos humanos, tanto do indivíduo como de grupos e comunidades mais complexas" (CERVO; BERVIAN; SILVA, 2007, p. 61). Desta forma, a pesquisa descritiva analisa os dados que são levantados e/ou observados na própria realidade. 


\section{Procedimentos éticos}

Primeiramente, o projeto foi apresentado à direção da instituição em que foi realizada a pesquisa para a obtenção da carta de autorização. Após a obtenção da carta, o projeto foi submetido e aprovado pelo Comitê de Ética da Universidade Federal de São Carlos, sob o parecer de número 1.332.517.

\section{Participantes}

Participaram da pesquisa, conforme as informações do Quadro 2, 15 pessoas, sendo cinco pessoas com síndrome de Down, com idades entre 15 e 35 anos, cinco pessoas próximas (uma para cada participante com SD), e os pais ou responsáveis das pessoas com síndrome de Down (somente um de cada pessoa com SD).

Quadro 1 - Caracterização dos participantes ${ }^{1}$

\begin{tabular}{llllll} 
Sexo & Idade & $\begin{array}{l}\text { Pessoa } \\
\text { próxima }\end{array}$ & $\begin{array}{l}\text { mais } \\
\text { Relação } \\
\text { sujeito }\end{array}$ & $\begin{array}{l}\text { com } \\
\text { P Responsável/ } \\
\text { Parentesco }\end{array}$ \\
\hline Masculino & 26 & PP1 & Noiva & R1-Mãe \\
\hline Feminino & 30 & PP2 & Pai & R2-Pai \\
\hline Feminino & 36 & PP3 & Pai & R3-Mãe \\
\hline Feminino & 27 & PP4 & Noivo & R4-Mãe \\
\hline Feminino & 30 & PP5 & Amiga & R5-Mãe \\
\hline
\end{tabular}

Fonte: Base de dados da pesquisa

\section{Local}

A pesquisa foi realizada em um Instituto de convivência de pessoas com síndrome de Down em uma cidade de pequeno porte no interior de São Paulo. Constitui-se por um instituto sem fins lucrativos que visa o auxílio no processo de inclusão nas escolas e no mercado de trabalho às pessoas com síndrome de Down. Os participantes frequentavam o Instituto uma vez por semana com atividades diversificadas visando a convivência.

\section{Materiais e equipamentos}

Foram utilizados gravadores, papel sulfite, impressora e computador portátil e filmadora.

\section{Instrumentos e coletas de dados}

Foram utilizados os seguintes instrumentos:

\footnotetext{
${ }^{1}$ n:15. P- Participante, PP- Pessoa Próxima R- Responsável.
} 


\section{Planilha de seleção de pessoas mais próximas}

DOI: 10.5902/1984686X27836

Elaborado pelas pesquisadoras, contendo perguntas voltadas para a identificação das pessoas que mais convivem com as pessoas com síndrome de Down em diferentes ambientes. Esta planilha foi respondida pelos pais e também pelas pessoas com SD. As Questões respondidas pelas pessoas com SD foram sete, sendo elas: Qual a pessoa que você mais convive no seu dia-a-dia? Com quem você mais gosta de conversar? Quem é o seu melhor amigo? Quando você está triste qual a primeira pessoa que você procura para conversar? Quando você está feliz com algo, com quem quer compartilhar essa alegria? Com quem você sai para passear? Quem é a pessoa que você considera ser mais próxima? A questões respondidas pelos pais foram sete, sendo elas: Qual a pessoa que ele mais convive no dia-a-dia? Com quem ele mais gosta de conversar? Quem é o melhor amigo dele? Quando ele está triste qual a primeira pessoa que ele procura para desabafar? Quando ele está feliz com algo, com quem ele quer compartilhar? Com quem ele (a) sai para passear? Qual a pessoa que você considera ser mais próxima dele?

\section{Questionário de Habilidades Sociais}

Questionário de Avaliação das Habilidades Sociais de Quitério (2010) adaptado a partir do Questionário de Habilidades Sociais de Zilda A. P. Del Prette para a percepção dos pais e pessoas mais próximas acerca das habilidades sociais de seus filhos e amigos com SD. Contemplando os aspectos das habilidades sociais como: habilidades básicas de comunicação; habilidades de autocontrole e expressividade emocional; habilidades de civilidade; habilidades empáticas; habilidades de fazer amizades; habilidades assertivas.

\section{Avaliação de Habilidades Sociais por meio de vídeos modelos}

Desenvolvida pelas pesquisadoras para avaliar a percepção das pessoas com SD acerca de suas próprias habilidades sociais com base no aplicativo Functional Skills System e no Questionário de Avaliação das Habilidades Sociais de Quitério (2010), a seguir, apresenta-se um modelo considerando uma questão do questionário para demonstração de como foram desenvolvidos os vídeos: 
DOI: $10.5902 / 1984686 \times 27836$

Avaliação das habilidades sociais em forma de vídeo
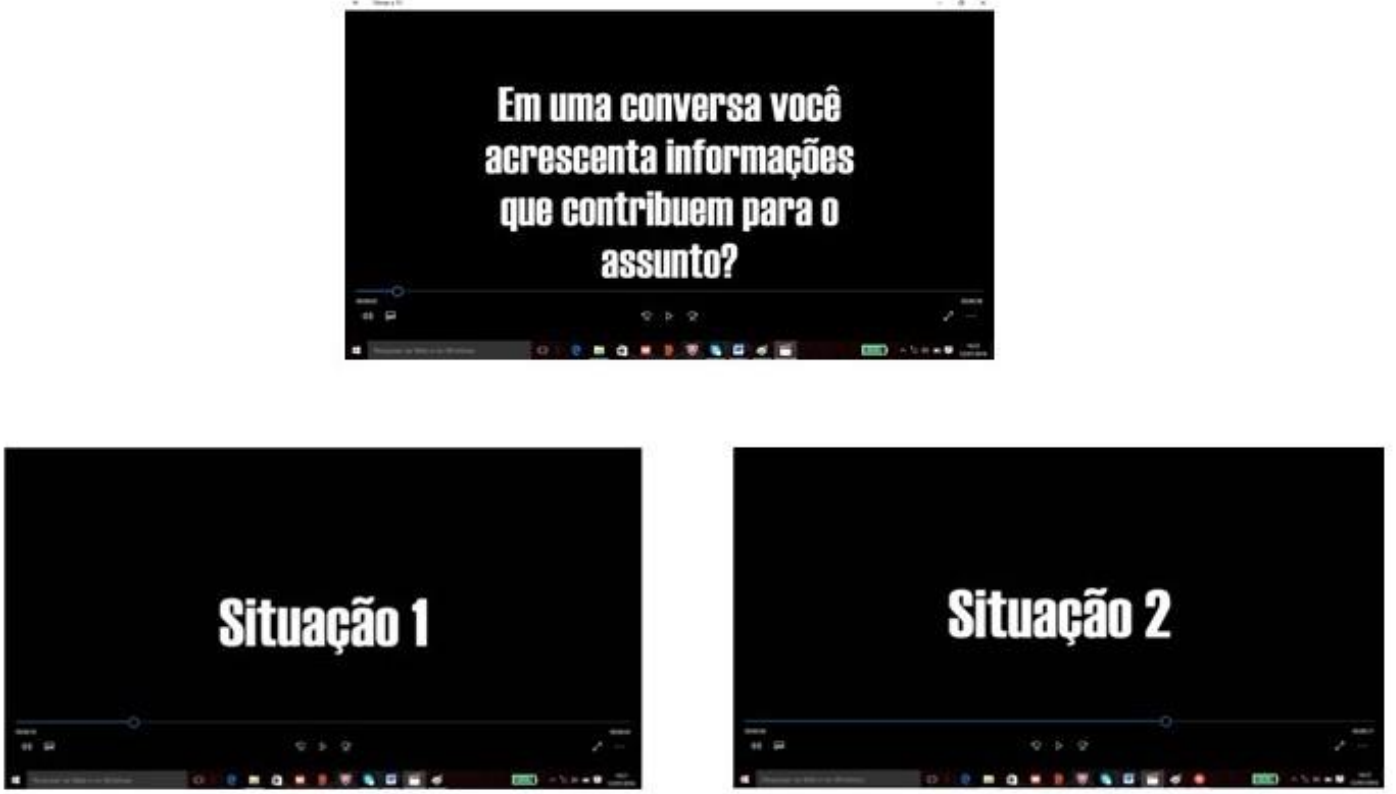

$\mathrm{Na}$ situação 1, as duas personagens estavam sentadas $\mathrm{Na}$ situação 2, as duas personagens estavam sentadas no chão ao lado da piscina, a personagem 1 diz a amiga no chão ao lado da piscina, a personagem 1 diz a amiga que foi mal em uma prova da faculdade, então a que foi mal em uma prova da faculdade, então a personagem 2 acrescenta uma informação que contribui personagem 2 não consegue acrescentar uma para 0 assunto, dizendo conhecer um lugar bom que dão informação que contribui para o assunto, dizendo para a aulas particulares, passando o telefone a amiga. amiga que abriu uma nova lanchonete sem dar importância para o que a personagem 1 estava dizendo.
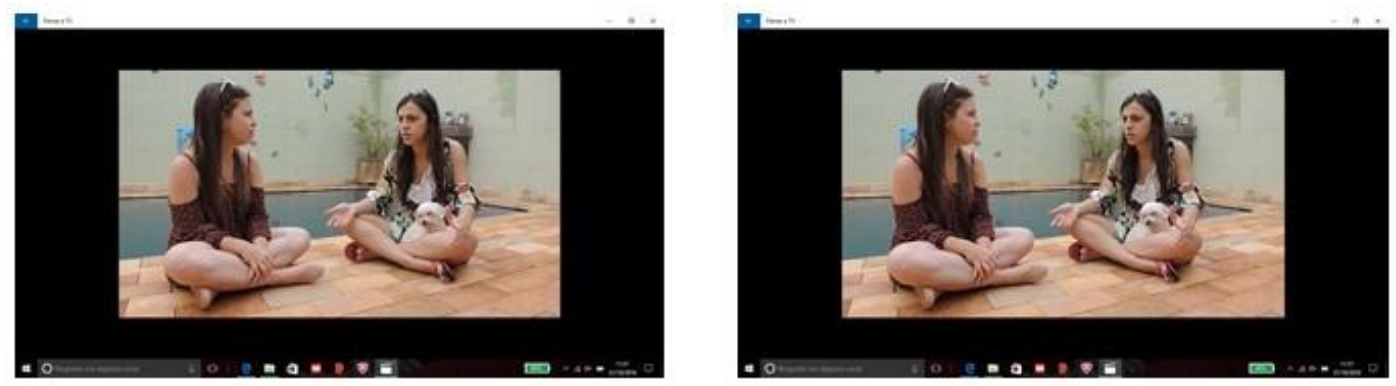

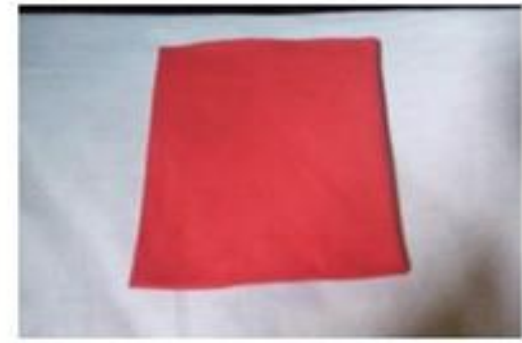

Nunca

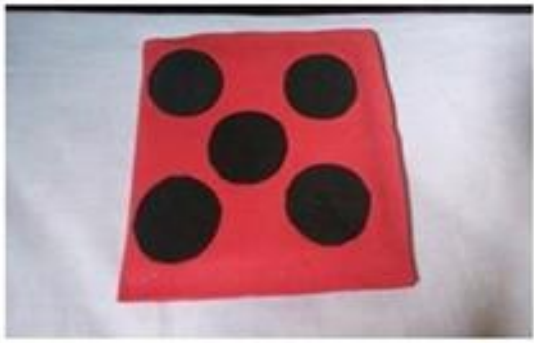

Sempre

Fonte: Base de dados da pesquisa 
DOI: $10.5902 / 1984686 \times 27836$

Foram elaborados os vídeos considerando os aspectos das habilidades sociais como: habilidades básicas de comunicação (quatro questões); habilidades de autocontrole e expressividade emocional (cinco questões); habilidades de civilidade (oito questões); habilidades empáticas (três questões); habilidades de fazer amizades (cinco questões); habilidades assertivas (cinco questões). Foram um total de trinta questões e para cada questão foram elaborados dois vídeos contemplando duas situações uma com o comportamento adequado para a situação e a outra com comportamento inadequado. A situação 1 e 2 era alternada para que os participantes não fossem induzidos à resposta. Após assistirem ao vídeo, as pesquisadoras sugeriram que os mesmos mostrassem a plaquinha que representassem mais suas atitudes nas duas situações, ou seja, assistiam à situação 1 e mostravam a plaquinha que mais representava a sua resposta. Assistiam à situação $2 \mathrm{e}$ mostravam a plaquinha que mais representava a sua resposta.

\section{Roteiro de Observação}

Foi desenvolvido um roteiro de observação para que as pesquisadoras pudessem confrontar as respostas obtidas pelo questionário com as observações, cada tópico tratavase da mesma ideia das perguntas utilizadas no questionário, servindo como base para a observação do grupo. O questionário utilizado como base para esse roteiro de observação foi embasado no questionário de Del Prette modificado por Quitério (2010). Habilidade de comunicação básica: Ele olha nos olhos da pessoa quando está conversando? Quando alguém se aproxima, ele se afasta ou inicia uma conversa? Presta atenção na conversa (concordando ou não)? O volume e as entonações são apropriados ao ambiente? Habilidade de autocontrole e expressividade emocional: É capaz de expressar facilmente seus sentimentos (alegria, raiva)? Como ele reage a críticas? Habilidade de civilidade: Cumprimenta as pessoas ao chegar e sair dos lugares? Ele se dirige as pessoas utilizando o nome delas? Ao conhecer uma pessoa, se apresenta com o seu nome? Quando precisa, pede licença e diz obrigado? Sabe adentrar em uma conversa já iniciada, educadamente? Sabe encerrar uma conversa de forma educada? Habilidade de empatia: Ele percebe sinais não verbais se a pessoa está interessada ou não na conversa? Ele sabe mediar a conversar deixando todos participarem da mesma? Ele demonstra interesse pelo outro (pergunta se está doente etc.)? Habilidade de fazer amizades: Apresenta capacidade de em uma conversa, acrescentar informações que contribuem para o assunto? Em atividades de grupo, 


\section{DOI: $10.5902 / 1984686 \times 27836$}

consegue emprestar ou solicitar algum objeto? Habilidade assertiva: Consegue negar pedidos educadamente? Consegue fazer pedidos educadamente?

\section{Procedimentos de coleta de dados}

Após a explicação minuciosa do projeto de pesquisa, foi agendado com os pais um dia para responderem ao Questionário de Habilidades Sociais e também para o preenchimento da Planilha de seleção de pessoas mais próximas, em que denominavam para as pesquisadoras quem era a pessoa mais próxima de seus filhos.

Em seguida foi elaborado o instrumento "Avaliação das habilidades sociais por meio de vídeos modelos". Após a elaboração dos vídeos, foram agendados os encontros com as pessoas com síndrome de Down para o início da Avaliação das Habilidades Sociais, em que eles assistiam ao questionário em forma de vídeos com exemplos das situações, após assistirem aos vídeos e responderem ao questionário, preencheram a planilha de seleção de pessoas mais próximas para que as pesquisadoras identificassem as pessoas que eles consideravam a mais próxima.

Foram analisadas as planilhas de seleção de pessoas mais próxima para que estas fossem identificadas e contatadas. Neste sentido, as pesquisadoras entraram em contato com estas pessoas para o agendamento referente à aplicação do Questionário de Habilidades Sociais.

Terminada as avaliações com os responsáveis, com as pessoas com síndrome de Down e com as pessoas mais próximas, iniciou-se o processo de análise dos dados.

\section{Procedimentos de análise de dados}

Por meio da análise de conteúdo foram elaboradas as possíveis categorias, em que participaram dois juízes para garantir a fidedignidade das mesmas. Bardin (2011), define análise de conteúdo como:

Um conjunto de técnicas de análise das comunicações visando a obter, por procedimentos sistemáticos e objetivos de descrição do conteúdo das mensagens, indicadores (quantitativos ou não) que permitam a inferência de conhecimentos relativos às condições de produção/recepção (variáveis inferidas) destas mensagens (BARDIN, 2011, p. 47). 
DOI: $10.5902 / 1984686 \times 27836$

Neste sentido, os dados foram primeiramente submetidos à análise, sendo realizadas as escolhas e levantamento de hipóteses. Num segundo momento com os dados já transcritos, realizou-se a leitura para a escolha das categorias que surgiram das questões norteadoras ou das hipóteses. E por fim, a interpretação dos dados para a apresentação dos resultados.

\section{Resultados}

Os dados coletados serão apresentados a seguir, considerando às subclasses das habilidades sociais, sendo essas: Habilidade de comunicação básica, Habilidade de autocontrole e expressividade emocional, Habilidade de civilidade, Habilidade de empatia, Habilidade de fazer amizades e Habilidade assertiva. Para cada subclasse serão apresentados os resultados referente à média das respostas da própria pessoa com SD, seus responsáveis e da pessoa mais próxima.

Figura 1 - Respostas referente às Habilidades Sociais de $\mathrm{P} 1^{2}$

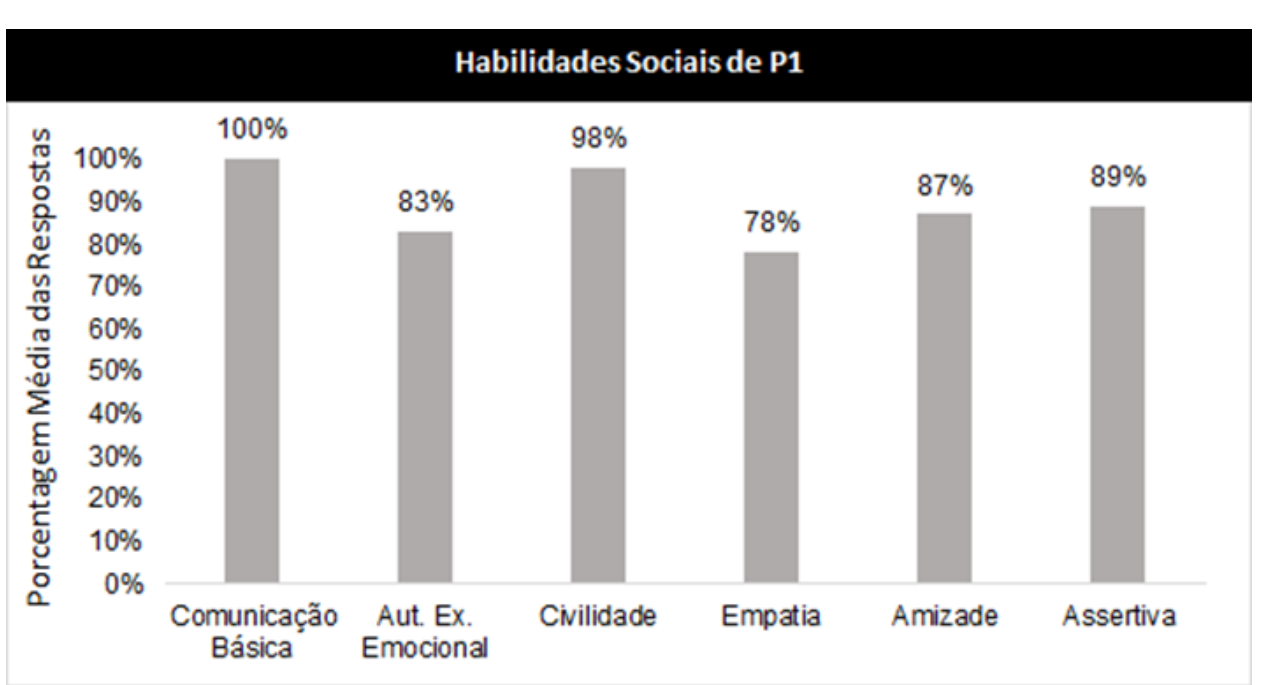

Fonte: Base de dados da pesquisa

Observa-se, na Figura 1, com relação às habilidades de comunicação, P1 obteve média de $100 \%$. Neste sentido, considera-se que ele olha sempre nos olhos das pessoas enquanto conversa, compreende as explicações dadas a ele, sempre mantendo a atenção, além de realizar generalizações das situações apresentadas nos

\footnotetext{
${ }^{2}$ Dados retirados a partir de uma escala Likert de cinco pontos: até $20 \%$ (nunca); de $21 \%$ a 39\% (poucas vezes); $40 \%$ a $59 \%$ (às vezes); $60 \%$ a $79 \%$ (Muitas vezes); $80 \%$ a $100 \%$ (sempre). $n=3$.
} 
DOI: $10.5902 / 1984686 \times 27836$

vídeos com situações reais de sua. Com relação à habilidade de autocontrole e expressividade emocional, o participante teve um resultado de $83 \%$. De acordo com as respostas, o participante sempre consegues expressar facilmente seus sentimentos, sempre justificando suas respostas, concordando ou não com as situações demonstradas. Manteve-se calmo durante toda a pesquisa, gostou muito dos vídeos em forma de questionário, demonstrando bastante interesse, sendo isso evidente em sua fala: "pode continuar que eu não tenho hora para ir embora".

Na habilidade de civilidade, P1 obteve média de 98\%. O participante sempre cumprimenta as pessoas ao chegar e sair dos lugares, dirige-se às pessoas utilizando os nomes delas. Ao conhecer uma nova pessoa, apresenta-se com o seu nome. Quando precisa pede licença e diz obrigado, o que pode ser comprovado através da observação, demonstrando ter um domínio na habilidade de civilidade. Com relação à habilidade de empatia, o participante obteve média de $78 \%$, considerando que muitas vezes consegue mediar a conversa deixando todos participarem, o que está em concordância com o observado e também que muitas vezes demonstra interesse pelo outro.

$\mathrm{Na}$ Habilidade de fazer amizades, pode-se notar que P1 sempre apresenta capacidade de acrescentar informações que contribuam para um assunto dentro de uma conversa e que sempre consegue emprestar ou solicitar objetos em grupos, obtendo média de $87 \%$. Na Habilidade Assertiva, pode-se observar na Figura 1, que P1 obteve média $89 \%$, considerando que sempre consegue negar e fazer pedidos educadamente. 
DOI: $10.5902 / 1984686 \times 27836$

Figura 2 - Respostas referente às Habilidades Sociais de P2

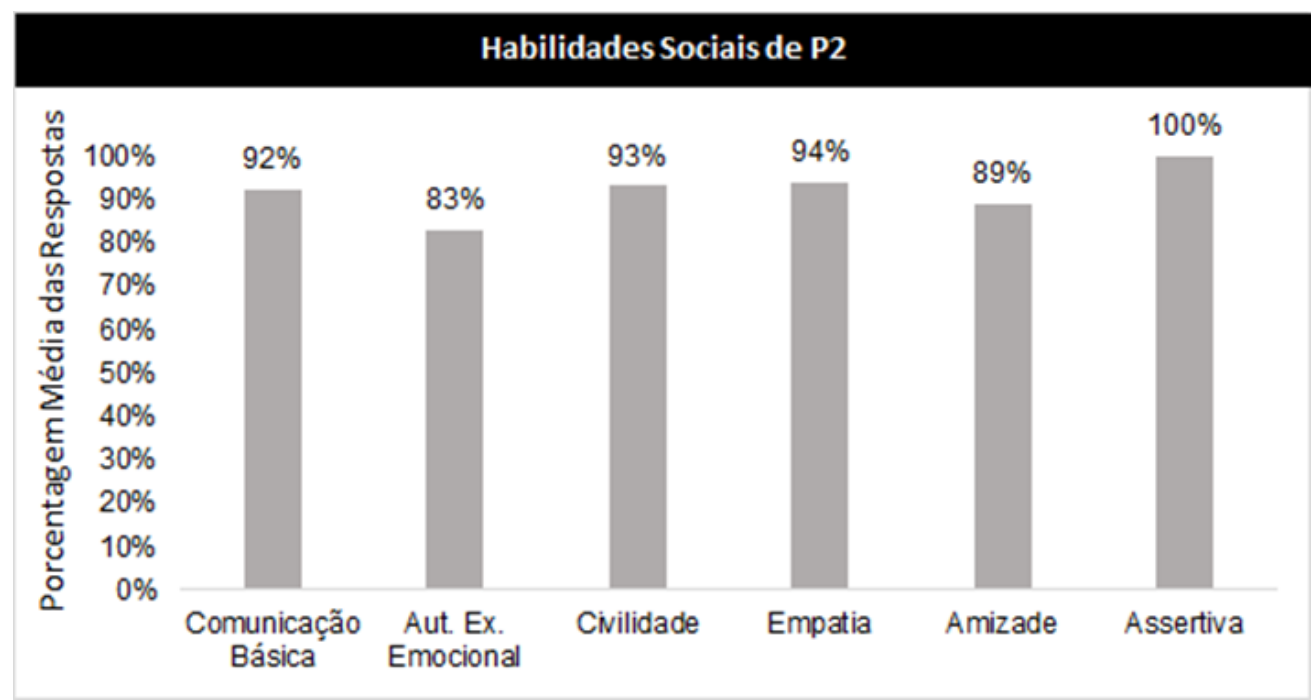

Fonte: Base de dados da pesquisa

De acordo com a Figura 2, a participante atingiu pontuação média de 92\% na habilidade de comunicação básica. A partir dos dados do questionário e da observação, foi possível notar que a participante mostrou olhar sempre nos olhos da pessoa quando está conversando. Mantém atenção durante uma conversa. $O$ volume e as entonações se mostraram totalmente adequados ao ambiente em que estava inserida. Porém, não conseguia generalizar os exemplos usados nos vídeos, ficando apenas nas situações demonstradas, ao invés de relacioná-los às experiências pessoais vividas. De acordo com Elliott (1985), pessoas com SD apresentam dificuldades em se adaptar às demandas escolares, dificuldade em generalizar experiências e alcançar níveis satisfatórios de aceitação social.

Com relação às Habilidades de autocontrole e expressividade emocional, de acordo com a Figura 2, P2 obteve uma média de $83 \%$. A participante demonstrou não sentir incômodos, expressando-se facilmente durante as respostas, mostrou gostar dos vídeos e sempre relatava episódios vivenciados por ela, relacionando suas experiências com as situações dos vídeos. Na habilidade de civilidade, P2 obteve uma média de 83\%, considerando que sempre cumprimenta as pessoas ao chegar e sair dos lugares. Quando conhece uma nova pessoa se apresenta com o seu nome. Dirige-se às pessoas utilizando os nomes delas. Sabe adentrar-se em uma conversa já iniciada de forma educada e pede licença e diz obrigado. 
DOI: $10.5902 / 1984686 \times 27836$

Na Habilidade de empatia, P2 demonstrou ter um domínio nessa habilidade, pois ela sempre deixava todos participarem durante uma conversa e também demonstrava interesse pelas pessoas, obtendo uma média de 94\%. Na Habilidade de fazer amizade, P2 obteve uma média de 89\%, em que sempre apresenta capacidade de acrescentar informações que contribuem para um assunto dentro de uma conversa, além de conseguir emprestar ou solicitar objetos em atividade de grupo. Na Habilidade assertiva, observando a Figura 2, notase que P2 obteve média de 100\%, considerando que sempre consegue fazer e negar pedidos educadamente e também sempre consegue acatar ordens.

Figura 3 - Respostas referente às Habilidades Sociais de P3

\section{Habilidades Sociais de P3}

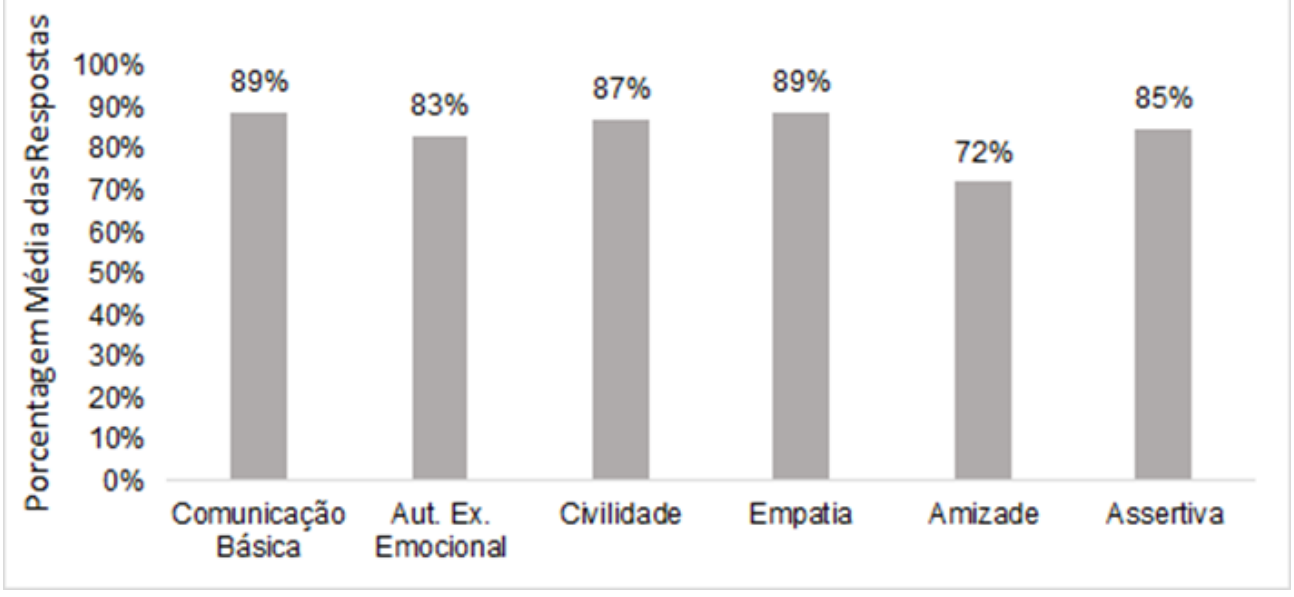

Fonte: Base de dados da pesquisa

Na habilidade de comunicação básica, P3 obteve média de 89\%. De acordo com os dados, a participante sempre olha nos olhos enquanto conversa. Presta atenção na conversa, mas distraindo-se várias vezes. Conversava muito pouco com as integrantes do grupo. Porém, suas entonações eram apropriadas para o ambiente em que estava. $\mathrm{Na}$ habilidade de autocontrole e expressividade emocional, P3 obteve 83\%. Devido ao fato da participante não conseguir expressar seus sentimentos, demonstrou-se um pouco nervosa e inquieta. Neste momento as pesquisadoras deram um tempo para a participante se acalmar. Assim que se acalmou, foram utilizadas explicações após a exibição dos vídeos para que a ela tivesse uma melhor compreensão da situação abordada nos vídeos.

Na habilidade de civilidade, observa-se na Figura 3 que P3 obteve média de 87\%. Sempre quando chega e sai de um lugar cumprimenta as pessoas. Dirige-se às pessoas 
DOI: $10.5902 / 1984686 \times 27836$

utilizando seus nomes. Apresenta-se com seu nome ao conhecer pessoas e consegue adentrar em uma conversa já iniciada educadamente, estando em consonância com as observações. Na habilidade de empatia, P3 observa-se que sempre consegue mediar às conversas deixando todos participarem, mas que só às vezes demonstra interesse pelos outros, obtendo média de $89 \%$.

Na habilidade de fazer amizade, verifica-se na Figura 3, que P3 obteve uma pontuação de $72 \%$, mesmo que a participante tenha uma pontuação baixa, ela muitas vezes tem facilidade em fazer amizades, é muito querida pelos outros participantes e fez amizade com as pesquisadoras facilmente. Muitas vezes apresenta capacidade de acrescentar informações que contribuem para um assunto dentro de uma conversa e muitas vezes empresta ou solicita objetos em atividade de grupo. Na habilidade assertiva, a porcentagem média da participante foi de $85 \%$, na qual sempre consegue negar e fazer pedidos educadamente e sempre consegue acatar ordens.

Figura 4 - Respostas referente às Habilidades Sociais de P4

\section{Habilidades Sociais de P4}

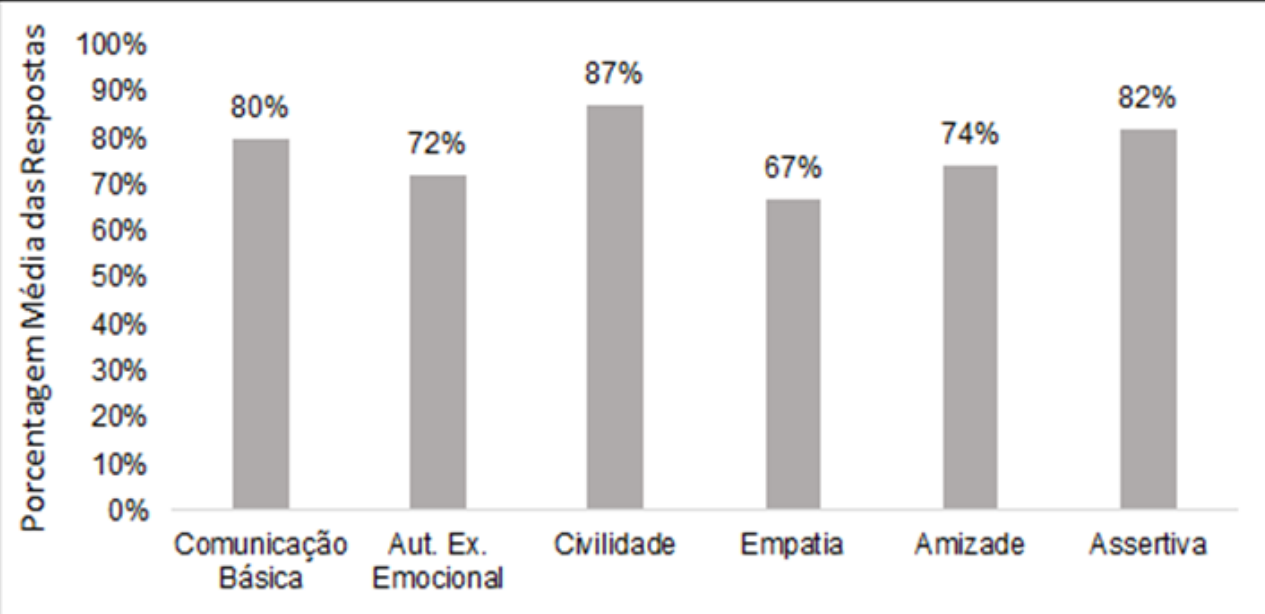

Fonte: Base de dados da pesquisa

Na habilidade de comunicação básica a participante P4 obteve um resultado de $80 \%$, conforme a Figura 4, o que em parte não confere com o observado, pois a participante se mostrou bem nervosa e desinteressada no início, não olhava nos olhos das pesquisadoras, não prestava muita atenção na conversa, comunicando-se o mínimo possível. Pode-se constatar a dificuldade da participante em manter a atenção na aplicação do vídeo e em outras situações. O estudo de Ekstein et al. (2011) constatou que a prevalência de déficit de 


\section{DOI: $10.5902 / 1984686 \times 27836$}

atenção em crianças com SD é bastante alta, chegando a 43,9\% de acordo com o critério do DSM-IV.

$\mathrm{Na}$ habilidade de autocontrole e expressividade emocional, segundo a Figura 4, P4 apresentou um resultado de $72 \%$ na habilidade de autocontrole e expressividade emocional, estando em consonância com o observado, pois, notou-se que a participante não demonstra facilmente seus sentimentos, devido ao fato da mesma estar um pouco tímida no início do questionário e um pouco nervosa. Muitas vezes reage bem às críticas, estando em consenso com o observado. Na habilidade de civilidade, a participante apresentou uma pontuação de $87 \%$, mostrando que sempre cumprimenta as pessoas ao chegar e sair dos lugares. Dirigese às pessoas utilizando o nome delas. Apresenta-se com o seu nome. Pede licença e diz obrigado. Sabe adentrar e encerrar em uma conversa educadamente.

Na habilidade de empatia obteve média de 67\%, sendo que muitas vezes consegue mediar uma conversa deixando todos participarem, porém durante toda a pesquisa a participante ficou muito quieta. Já em outra questão, no qual abordava o assunto de mostrar o interesse por outras pessoas, muitas vezes demonstra interesse. Na habilidade de fazer amizade, segundo a Figura 4, P4 muitas vezes apresenta capacidade de, durante uma conversa, acrescentar informações que contribuem para o assunto e que muitas vezes, em atividades de grupo, consegue emprestar ou solicitar algum objeto, somando uma porcentagem de $74 \%$.

Na habilidade assertiva, pôde-se notar que P4 obteve porcentagem de $82 \%$, sendo que sempre consegue fazer pedidos educadamente e esse fato pode ser observado em uma das situações durante a observação, sempre consegue acatar ordens e sempre consegue negar pedidos educadamente. 
DOI: $10.5902 / 1984686 \times 27836$

Figura 5 - Respostas referente às Habilidades Sociais de P5

\section{Habilidades Sociais de P5}

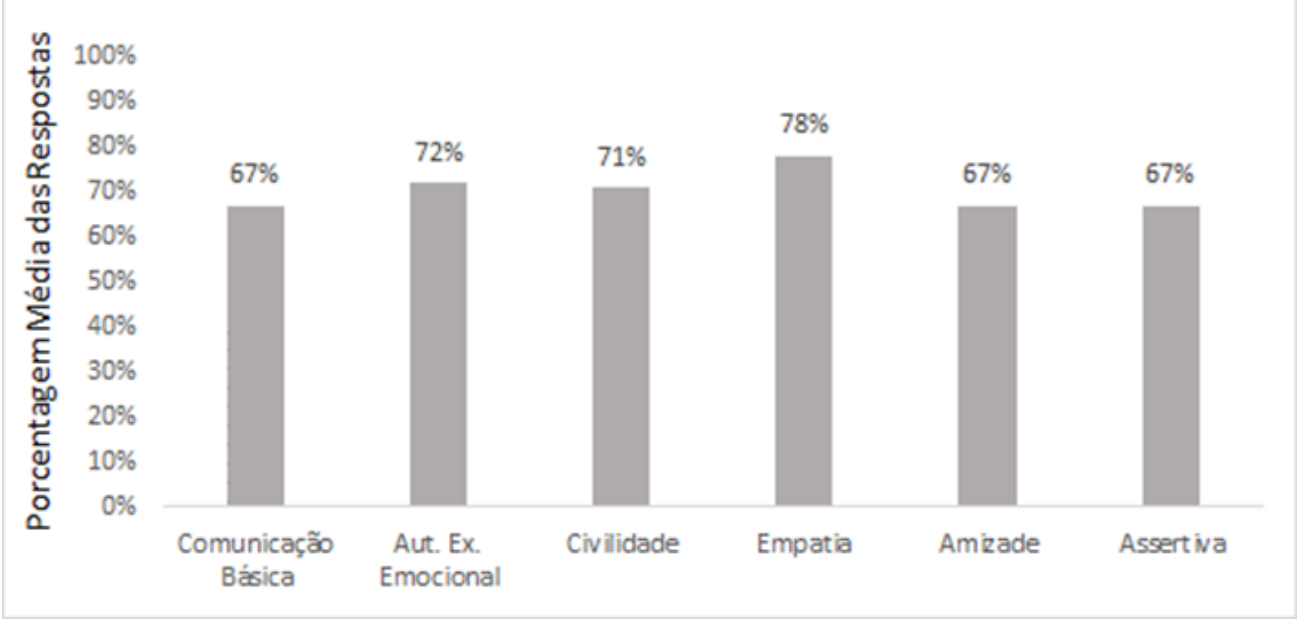

Fonte: Base de dados da pesquisa

A participante P5 obteve $67 \%$ na habilidade de comunicação básica, apresentou maior dificuldade durante a realização do questionário, não olhando muito nos olhos das pesquisadoras; se distraia com coisas aleatórias, ao invés de prestar atenção na conversa em que estava inserida. De acordo com Angélico e Del Prette (2011) há grande variabilidade existente entre cada indivíduo com SD com relação ao repertório de habilidades sociais. Neste sentido, declaram que "é preciso considerar também que as pessoas apresentam uma variedade de respostas sociais frente a diferentes situações e momentos" (ANGÉLICO; DEL PRETTE, 2011, p. 215), com isso seu comportamento pode mudar decorrente do ambiente físico em que ele está no momento, dos indivíduos com quem está interagindo e da natureza da interação.

Quanto à habilidade de autocontrole e expressividade emocional, P5 obteve pontuação de $72 \%$, podendo ser observado que a participante mostrou ter essa habilidade muitas vezes, apresentando seus sentimentos, expondo sua opinião a todo o momento. Muitas vezes é capaz de expressar seus sentimentos e que também muitas vezes reage bem a críticas. $\mathrm{Na}$ habilidade de civilidade, nota-se que P5 apresenta um resultado de $71 \%$, em apresentou muitas vezes cumprimenta as pessoas ao chegar e sair dos lugares. Muitas vezes dirige-se às pessoas utilizando o nome delas. Muitas vezes apresenta-se com o seu nome. Muitas vezes pede licença e diz obrigado e sabe adentrar e encerrar em uma conversa educadamente. 


\section{DOI: $10.5902 / 1984686 \times 27836$}

Na habilidade de empatia, segundo a Figura 5, P5 obteve média de 78\%, considerando que muitas vezes consegue mediar uma conversa deixando todos participarem da mesma, o que está em concordância com o observado pelas pesquisadoras e que muitas vezes demonstra interesse pelos outros. Na habilidade de fazer amizade, nota-se na Figura 5, que P5 obteve uma pontuação de $67 \%$, sendo que a mesma, por meio da observação demonstrou ter facilidade em fazer amizades, porém a mesma respondeu que às vezes apresenta capacidade de em uma conversa, acrescentar informações que contribuam para o assunto dentro de uma conversa e que às vezes consegue emprestar ou solicitar objetos em atividades de grupo.

O responsável teve uma percepção na habilidade de fazer amizades de $67 \%$, sendo que muitas vezes empresta e solicita objetos em uma atividade de grupo e muitas vezes apresenta capacidade de acrescentar informações que contribuem para o assunto durante uma conversa. Na habilidade assertiva, P5 obteve uma pontuação de $67 \%$, na qual observase que muitas vezes consegue negar e fazer pedidos educadamente e também muitas vezes consegue acatar ordens.

\section{Conclusão}

Este estudo possibilitou uma nova proposta de avaliação das pessoas com SD a partir de suas próprias percepções acerca de suas habilidades sociais. De acordo com a literatura, muitos estudos apontam avaliações de tais habilidades, no entanto em relação à percepção das pessoas com deficiência há uma escassez na área, considerando a grande dificuldade das pessoas com deficiência, principalmente a deficiência intelectual, em compreenderem o que está sendo perguntado e a exigência na complexidade das respostas.

Decorrente do fato do vídeo ser uma explicação da pergunta em formato visual e dinâmico, favoreceu a compreensão e a atenção dos participantes, pois a maior parte manteve a atenção durante a exibição do vídeo e conseguiu compreender o que estava sendo perguntado.

A resposta por meio de plaquinhas que deveriam ser levantadas pelos participantes, sendo que a primeira plaquinha continha muitas, poucas e nenhuma bolinha, significando a resposta de "nunca" à "sempre". As respostas por meio das plaquinhas reduziram a 
DOI: $10.5902 / 1984686 \times 27836$

dificuldade de compreensão dos conceitos: nunca, às vezes e sempre, além de reduzir a dificuldade na linguagem expressiva que é própria das pessoas com SD.

Este trabalho contribuiu para o levantamento das habilidades sociais que necessitam de intervenção, a partir das respostas fornecidas pelas pessoas com SD, seus responsáveis e pessoas próximas a eles. Cada pessoa com SD tem suas particularidades, apresentando melhores habilidades em diferentes áreas, além de particularidades em suas dificuldades e facilidades, ou seja, não podemos generalizar considerando que as pessoas com síndrome de Down são iguais em suas dificuldades e habilidades, muitas vezes as percepções dos seus responsáveis não são as mesmas que eles têm deles mesmos.

Pode-se observar que houve uma variação nas habilidades de cada participante, considerando que cada um pode ter limitações específicas em algumas habilidades sociais. Os participantes P1, P3 e P4 obtiveram pontuações mais baixa nas habilidades de empatia, P2 na habilidade de autocontrole e expressividade emocional e P5 nas habilidades de amizade, comunicação e assertividade. Assim, podemos concluir que em cada um dos participantes deve-se desenvolver um programa específico de habilidades sociais que esteja direcionado às habilidades mais críticas em cada indivíduo.

É importante ressaltar que há necessidade de expansão de trabalhos relacionados a esse assunto, pois há poucos estudos que abordam a síndrome de Down e as habilidades sociais. Pesquisas futuras poderiam replicar a avaliação por meio dos vídeos em uma amostra mais significativa e também em diferentes públicos da área da educação especial.

\section{Referências}

ANGÉLICO, Antonio Paulo; DEL PRETTE, Almir. Avaliação do repertório de habilidades sociais de adolescentes com Síndrome de Down. Psicologia: Reflexão e Crítica, v. 24, n. 2, p. 207-217, 2011.

BARDIN, Laurence. Análise de conteúdo. São Paulo: Edições 70, 2011.

BONOMO, Lívia Maria Marques; GARCIA, Agnaldo; ROSSETTI, Claudia Broetto. O adolescente com síndrome de Down e sua rede de relacionamentos: Um estudo exploratório sobre suas amizades. Psicologia: Teoria e Pesquisa, v. 11, n. 3, p. 114-130, 2009.

CERVO, Amado L.; BERVIAN, Pedro A.; SILVA, Roberto da. Metodologia científica. 6. ed. São Paulo: Pearson Prentice Hall, 2007 


\section{DOI: $10.5902 / 1984686 \times 27836$}

DEL PRETTE, Almir; DEL PRETTE, Zilda Aparecida Pereira. Psicologia das habilidades sociais: terapia e educação. Petrópolis: Vozes, 1999.

DEL PRETTE, Zilda Aparecida Pereira; DEL PRETTE, Almir. Avaliação multimodal de habilidades sociais em crianças: Procedimentos, instrumentos e indicadores. In: BANDEIRA, Marina; DEL PRETTE, Zilda; DEL PRETTE, Almir. (Org.). Estudo sobre habilidades sociais e relacionamento interpessoal. São Paulo: Casa do Psicólogo, 2006.

ELLIOTT, Digby. Manual asymmetries in the performance of sequential movement by adolescents with Down syndrome. American Journal of Mental Deficiency, v. 90, n.1, p. 90-97, 1985.

EKSTEIN, Silvan. et al. Down Syndrome and Attention-Deficit/Hyperactivity Disorder (ADHD). Journal of Child Neurology, v. 26, n. 10, p. 1290-1295, 2011.

GREENSPAN, Stephen; GRANFIELD, James. M. Reconsidering the construct of mental retardation: Implications of a model of social competence. American Journal on Mental Retardation, v. 96, n.1, p. 442-453, 1992.

GRESHAM, Frank M. Assessment of social skills in students with emotional and behavioral disorders. Assessment for Effective Intervention, v. 26, n.1, p. 51-58, 2000.

KOZMA, Chahira. O que é Síndrome de Down. In: STRAY-GUNDERSEN, Karen (Org.). Crianças com Síndrome de Down: guia para pais e educadores. Porto Alegre: Artmed, 2007.

PEREIRA-SILVA, Nara Liana; DESSEN, Maria Auxiliadora. Crianças com síndrome de Down e suas interações familiares. Psicologia: Reflexão e Crítica, v. 16, n.3, p. 503-514, 2003.

QUITÉRIO, Patrícia Lorena. Avaliação das Habilidades Sociais de jovens com Paralisia Cerebral usuários de Comunicação Alternativa. Dissertação (mestrado), Universidade do Estado do Rio de Janeiro, Faculdade de Educação, 2010, 201 f.

SORESI, Salvatore; NOTA, Laura. Social skill training for persons with Down's syndrome. European Psychologist, v. 5, n.1, p. 33-43, 2000.

VAN GAMERON-OOSTEROM, Helma .B.M. et al. Practical and social skills of 16-19-yearolds with Down syndrome: Independence still far away. Research in Developmental Disabilities, v. 34, n. 12, p 4599-4607, 2013. 


\section{Correspondência}

Viviane Rodrigues - Faculdades Integradas de Jaú, R. Ten. Navarro, 642, Chácara Braz Miraglia, CEP: 17207-310, Jaú, São Paulo, Brasil.

\section{(c) (i) \&}

Th is work is licensed under a Creative Commons Attribution-NonCommercial 4.0 International (CC BY-NC 4.0) 